ISSN: 0213-2052 - eISSN: 2530-4100

DOI: https://doi.org/10.14201/shha2021395172

\title{
PISÍSTRATO Y EL EPISODIO DEL CARRO DE ATENEA. NUEVA PROPUESTA DE DATACIÓN ${ }^{1}$
}

\section{Peisistratos and the Chariot of Athena Episode. A Chronological Reappraisal}

\author{
Unai IRIARTE \\ Universidad de Sevilla \\ uiriarte@us.es
}

Fecha de recepción: 23-4-2020 Fecha de aceptación: 3-11-2020

ORCID: https://orcid.org/0000-0002-3166-5887

RESUMEN: El episodio de Pisístrato volviendo en un carro junto a Atenea es uno de los acontecimientos mejor conocidos del período griego arcaico. Siguiendo sobre todo a Heródoto y a Aristóteles, la historiografía moderna actual lo sitúa tras su primer exilio y antes de la consecución de su segunda tiranía. Esta consideración plantea una serie de problemas, como el papel de Atenea en un acuerdo prenupcial. Por ello, a través de un estudio pormenorizado de las fuentes, así como del contexto histórico, proponemos aplazar esta entrada teatralizada al 546, cuando se produce la batalla de Palene y poco antes de que Pisístrato se instaure como tirano por tercera y última vez. Esta nueva cronología asienta mejor algunas interpretaciones que se han venido dando, pero también permite, a su vez, novedosas lecturas sobre los medios de legitimación religiosos y sociales empleados por el tirano de Atenas ${ }^{2}$.

1. El presente artículo ha contado con la financiación del VI Plan Propio de la Universidad de Sevilla. Asimismo, quisiera agradecer a César Fornis sus correcciones en algunos de los borradores previos de este trabajo.

2. A menos que se indique lo contrario, todas las fechas deberán considerarse a. C. 
Palabras clave: Pisístrato; tiranía; Heródoto; Aristóteles; Atenas arcaica; historiografía griega.

ABSTRACT: The episode of Peisistratos going back to Athens in a chariot with Athena is one of the best-known events of the Greek archaic period. Following Herodotus and Aristotle, the current modern historiography places it after his first exile and before he gets his second tyranny. This consideration raises up a series of problems, like the role of Athena in a prenuptial agreement. For this reason, through a detailed study of the sources, as well as the historical context, we propose to delay this dramatized entry to 546, when the battle of Palene occurs and shortly before Peisistratos was installed as a tyrant for the third and last time. This new chronology better supports some interpretations that have been already given, but also allows, in turn, novel readings on the means of religious and social legitimation used by the tyrant of Athens.

Keywords: Peisistratos; tyranny; Herodotus; Aristotle; Archaic Athens; Greek historiography.

La instrumentalización de Atenea por parte de Pisístrato tiene un origen claro y concreto. Es prácticamente communis opinio, tanto en la historiografía antigua como en la moderna, que se produjeron dos expulsiones y tres accesos al poder por parte del tirano ${ }^{3}$. La primera tiranía la habría conseguido fingiendo que sus enemigos le habían atacado, lo que le habría proporcionado una guardia personal (Hdt. 1.59.5-6; Arist. Rh. 1357b29-37; Ath. Pol. 14.1; Diod. Sic. 9.20.2; Ael. VH 8.16; Diog. Laert. 1.66). La segunda la alcanzó después de un pacto con Megacles, a cambio de casarse con su hija (Hdt. 1.60.2-61.1; Arist. Ath. Pol. 14.4; Plut. Mor. 858c). Y la tercera tras la batalla de Palene (Hdt. 1.62.3-63.2; Arist. Ath. Pol. 15.2-3; Polyaenus, Strat. 1.21). Este esquema está comúnmente aceptado, pero no sucede lo mismo con el episodio del retorno de Pisístrato en un carro junto a Atenea.

Para la mayor parte de la historiografía actual, que sigue fundamentalmente a Heródoto, el retorno del carro se habría producido tras la primera expulsión y segunda vuelta al poder de Pisístrato ${ }^{4}$. Sin embargo, hay

3. La cronología sí sigue generando cierta controversia. La única fuente antigua que habla de más de dos expulsiones es una inscripción helenística votiva de importancia menor (Anth. Pal. 11.442).

4. La bibliografía a este respecto es ingente, por poner algunos ejemplos: Gernet, "Mariages", 41-53; Connor, "Tribes, Festivals", 40-50; Sinos, "Divine Selection», 73-91; Shear, Polis; Forsdyke, Exile, 113-114. Para Lavelle, Fame, 101-102, que el episodio del carro se produjera en el ascenso de Pisístrato a su segunda tiranía "Was obviously the best time 
también voces (las menos, como Beloch o Blok) ${ }^{5}$ que apuntan a que esta escenografía se habría llevado a cabo tras la batalla de Palene. Otros autores evitan pronunciarse o posicionarse sobre este aspecto, o bien se limitan a considerar que se trataría de una historia ficticia que ni siquiera tuvo lugar ${ }^{6}$. En este trabajo nuestro fin es posicionarnos de manera clara entre una de estas posturas y demostrar que, a pesar de no gozar de demasiada acogida en la historiografía, existen razones suficientes para considerar que dicho episodio tuvo lugar en el 546, antes de la tercera instauración de Pisístrato como tirano ${ }^{7}$.

for it». Da cuatro argumentos, de los cuales, ya tres de ellos permiten situar este episodio en un segundo regreso. En el último restante, acepta la secuencia de los hechos porque habrían sido muchos los que habrían presenciado esta vuelta. Sin embargo, creemos que este no es un argumento demasiado convincente. Heródoto tiene la misma posibilidad de errar que cualquier otra fuente (por muchos testigos que hubiese), a lo que hay que añadir que escribe más de un siglo después en un en un mundo que se sirve de una tradición eminentemente oral que reelabora el pasado. Y más un pasado en el que se ven involucrados personajes de la talla de Megacles, que es Alcmeónida, y cuya memoria varía en el período clásico. Sobre este gran vacío histórico entre la primera y la segunda tiranía, que Heródoto habría tratado de llenar con su digresión sobre los Pisistrátidas, también muestra su escepticismo Sancisi-Weerdenburg, "Cultural Politics", 105.

5. Beloch, «Wann lebten», 465-473; Blok, «Phye's Procession», 17-48. Por «error» lo hace Hammond, A History, 165, pues no entra en discusión alguna sobre por qué establece entonces el episodio, desoyendo a Heródoto. No nos ha sido posible encontrar a ningún otro autor que defienda esta idea. Beloch, "Wann lebten", 469-470, lo hace porque cree, desoyendo otras fuentes, que Pisístrato tan solo se habría exiliado una vez. Blok, "Phye's Procession", 44-45, por su parte, no tiene en cuenta el contexto de las Grandes Panateneas, que creemos importante, sino que atiende a las similitudes que existen con la ceremonia del triunfo en Roma o con otras de reyes orientales, aunque la propia autora acepta que el supuesto conocimiento de Pisístrato sobre estas tradiciones se basa en meras suposiciones.

6. Para Adcock, «The exiles», 181, esta teatralización sería falsa. Para Rose, "Some Herodotean Rationalisms", 81, se trataría simplemente de un fraude, de una historia construida a posteriori por parte del tirano a través de la cual convencería a aquellos menos educados y más ignorantes políticamente. Moon, "The Priam painter", 101, se limita a considerarlo un cuento popular («a folktale») y no especula sobre su origen.

7. Damos por válida, como la mayoría de historiadores, que la batalla de Palene tuvo lugar en dicho año (cf. inter alia Adcock, "The exiles», 181; Hurwit, The Art, 236; SteinHölkeskamp, "Tirannidi», 672; Shapiro, Art and cult, 2, 104; Singor, "The military side», 112; Carty, Polycrates, 121; Van Wees, "Citizens», 117; Lavelle, Fame, 117; Archaic Greece, 26, 43). Para Wallace, «The Early Coinages», 36, las Wappenmünzen comenzarían a aparecer tras ese mismo año. Llama la atención, casualmente, que en algunas de estas monedas se represente un carro. La fecha de 536, que se obtiene si seguimos únicamente a Aristóteles (Ath. Pol. 15) y no a Heródoto, sería consecuencia de un malentendido del Estagirita (cf. Rhodes, A Commentary, 197). Y lo mismo sucede con Andócides (1.106), que parece situarla en torno a 510 porque tiene la necesidad de mostrar a sus ancestros como defensores de la democracia (cf. Larran, «La bataille», 70). 


\section{Fuentes para el ESTUdio del CAso}

No todas las fuentes antiguas que hablan sobre Pisístrato y su tiranía lo hacen también de cada una de sus expulsiones. Y son menos aún las que se refieren al episodio del carro. La primera que nos transmite este acontecimiento, que debía de ser ampliamente conocido entre los atenienses del siglo V, es Heródoto. En el primer libro de las Historias, en su digresión sobre la tiranía de Pisístrato, el de Halicarnaso cuenta que con el fin de volver a Atenas tras su primer exilio el futuro tirano habría

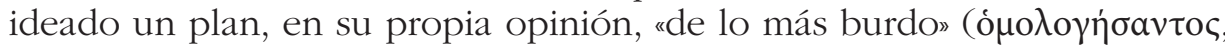
Hdt. 1.60.3). Esto le lleva incluso a dudar de que tuviera lugar: «Si es que efectivamente ellos pusieron en práctica algo semejante en Atenas, cuyos habitantes tienen fama de ser los griegos de más acusada grandeza” (ibid. $)^{8}$. Después añade sobre este asunto lo siguiente:

En el demo de Peania había una mujer, cuyo nombre era Fía, de cuatro codos menos tres dedos de estatura y, además, agraciada. Ataviaron a la mujer en cuestión con una armadura completa de hoplita, la hicieron subir a un carro, le indicaron la actitud que debía adoptar para aparentar mayor majestuosidad y la condujeron a la ciudad, enviando por delante heraldos que, al llegar a Atenas, proclamaron lo que les había sido ordenado, diciendo así: "Atenienses, acoged con propicia disposición a Pisístrato, a quien la propia Atenea, honrándolo más que a hombre alguno, repatria a su acrópolis». Los heraldos, pues, difundían estas palabras por todas partes y, en seguida, llegó a los demos el rumor de que Atenea repatriaba a Pisístrato; y los de la ciudad, convencidos de que la mujer era la diosa en persona, adoraron a aquella mortal y aceptaron a Pisístrato. Después de haber recobrado la tiranía del modo que he expuesto, Pisístrato, con arreglo al acuerdo pactado con Megacles, se casó con la hija de este último. (Hdt. 1.60.4-61.1)9

Como se puede apreciar en las últimas líneas, Heródoto (o su fuente) cree que este retorno se correspondería con la primera vuelta de Pisístrato al poder. Tras ello, narra una serie de hechos intermedios, como la nueva expulsión del tirano al no dar descendencia a la hija de Megacles y su posterior exilio en la Calcídica tracia, desde donde se estuvo preparando para la posterior batalla de Palene:

8. Traducción de C. Schrader. Ni siquiera hay acuerdo entre los historiadores sobre si Heródoto realmente confía en la historicidad del episodio (por ejemplo, Adcock, "The exiles", 181, piensa que sí; Asheri, "Book I", 122, que no y Parker, Athenian Religion, 83, incluso defiende que ni siquiera lo habrían creído los atenienses).

9. Traducción de C. Schrader. 
Partiendo, pues, de Eretria, regresaron [Pisístrato, sus hijos y el resto que marchara con él] al cabo de diez años, siendo Maratón la primera plaza del Ática que tomaron. Y, mientras estaban acampados en ese lugar, llegaron sus partidarios de la ciudad, y de los demos afluyeron otros, a quienes agradaba más la tiranía que la libertad; estos grupos fueron, pues, congregándose. [...] Y mientras los de la ciudad iban con todos sus efectivos al encuentro de los que pretendían regresar, las tropas de Pisístrato, cuando desde Maratón se dirigían contra la ciudad, se toparon con ellos al llegar al santuario de Atenea Palénide y plantaron sus reales frente a ellos. [...] Entonces Pisístrato [...] lanzó su ejército al ataque. Justamente en aquel preciso instante los atenienses de la capital se habían puesto a almorzar y algunos otros, tras el almuerzo, se hallaban jugando a los dados o durmiendo. Las tropas de Pisístrato cayeron, entonces, sobre ellos y los pusieron en fuga. Y, mientras huían, Pisístrato puso en práctica una idea muy inteligente en aquellas circunstancias para que los atenienses no volvieran a agruparse y continuaran dispersos. Hizo montar a sus hijos a caballo mandándolos en descubierta. Y ellos, a medida que se topaban con los fugitivos, les decían lo que les había encargado Pisístrato, aconsejándoles que conservaran la calma y que cada cual volviera a su casa. (Hdt. 1.62.1-63.2) ${ }^{10}$

Aunque aparentemente estos dos episodios no correspondan al mismo momento histórico en la narrativa herodotea, porque remiten a exilios distintos, con una diferencia cronológica de hasta diez años, presentan ciertas similitudes que nos empujan a creer que, si bien no hay razones para dudar de que se llevase a cabo ese trato con Megacles en lo respectivo al primer regreso ${ }^{11}$, no sucede lo mismo con la presencia del carro con Atenea. Su mera existencia plantea, de entrada, la pregunta de cuál era su razón de ser dentro de esta situación de acuerdo prenupcial.

Este punto de la digresión sobre la tiranía de los Pisistrátidas en Heródoto puede tener dos lecturas. Por un lado, en clave literaria, pues aunque este episodio pudo haber sucedido, no lo habría hecho en el momento en el que el mismo Heródoto lo sitúa, en el primer regreso de Pisístrato, sino en su segundo. A través de esta interpretación podríamos explicar la presencia de dicha teatralización por cuestiones mnemotécnicas. La obra del de Halicarnaso estaba concebida para ser escuchada por una determinada audiencia. Era importante para el propio Heródoto ser capaz de recordar

10. Traducción de C. Schrader.

11. No es objeto de debate entre las fuentes antiguas (Hdt. 1.60.1-3, refrendado por Arist. Ath. Pol. 14.3-4). Ni siquiera Plutarco, que en Sobre la malevolencia de Heródoto (Mor. 858c) protesta enérgicamente sobre el trato de Heródoto a la familia Alcmeónida, niega que este pacto se llevase a término. 
la sucesión de los acontecimientos, lo que le llevaba a crear patrones que le eran útiles para conectar un hecho con el siguiente ${ }^{12}$. ¿Qué mejor manera de recordar que lo acontecido en el segundo regreso de Pisístrato tenía que ver con el templo de Atenea Palénide si en el primer retorno contó ya con la presencia de la diosa?

Esta explicación no es suficientemente convincente por sí sola a la hora de desplazar el episodio del carro, pero puede complementarse con un análisis más profundo de la obra y su autor. Cabe recordar que otro de los objetivos de Heródoto era mantener a la audiencia atenta a su relato. Esta prestaría mayor atención al papel de Atenea en el primer retorno que al acuerdo al que Pisístrato había llegado con Megacles a cambio de que se le facilitara la tiranía. Como historiador, el de Halicarnaso tenía la obligación "moral» de transmitir este acuerdo entre el Alcmeónida y el Pisistrátida, pero este punto quedaría ante el público en un segundo plano por un regreso tan particular. Nos resulta demasiado audaz, sin embargo, plantear que el propio Heródoto llevase a cabo esta manipulación de la historia de manera consciente, por lo que seguramente debamos buscar una explicación de este anacronismo en una fuente alcmeónida cercana que pretendiera situar el foco en lo excepcional del retorno, en Pisístrato junto a una Atenea disfrazada, y no en el acuerdo de Megacles y el futuro tirano. De ahí que Heródoto no se muestre seguro del todo al afirmar lo sucedido.

Asimismo, este episodio también puede tener una lectura en clave histórica, mediante la cual podemos discernir cuáles eran las intenciones de Heródoto al transmitir un episodio que, al menos para sus fuentes, debía de ser real ${ }^{13}$. A priori no tenemos por qué negar que sucediese, pero sí creemos que incluso dentro del propio desarrollo histórico que nos transmite el de Halicarnaso tiene mucho más sentido que esta actuación «teatral» fue llevada a cabo por Pisístrato en su tercer y último acceso a la tiranía en 546.

Antes de nada, conviene atender también al resto de fuentes que se pronuncian sobre el episodio del carro, y ver por qué lo sitúan, mayoritariamente y al igual que Heródoto, en el primer regreso de Pisístrato y no en el segundo. La primera fuente tras el de Halicarnaso en referirse a la

12. Por ejemplo, durante su digresión de la tiranía de los Pisistrátidas (Hdt. 1.59-64), Heródoto acostumbra a hacer una división tripartita de los hechos. Tres son los consejos que Quilón da al padre de Pisístrato, a Hipócrates (no casarse, no tener hijos, renunciar a su hijo en caso de tenerlo; Hdt. 1.59.1-2); tres las facciones del Ática que continúan la narración (Hdt. 1.59.3), y que lo ayudan a explicar la situación previa a la tiranía, y también son tres las veces que Pisístrato acaba gobernando Atenas como tirano (Hdt. 1.64).

13. Como recuerda Sinos, "Divine Selection", 73, todos los autores antiguos lo consideran histórico. 
vuelta del futuro tirano junto a Atenea es Aristóteles. En la Constitución de los atenienses, ya en el último tercio del siglo IV, cuenta que tanto Pisístrato como Megacles habrían ideado esta estratagema:

[Megacles] hizo correr el rumor de que Atenea traía a Pisístrato, y habiendo encontrado una mujer alta y hermosa, según dice Heródoto (la cursiva es nuestra), del demo de los Peanieos, o como algunos dicen, una tracia del demo de Colito que vendía coronas, de nombre Fía, la adornó a imitación de la diosa y la introdujo en la ciudad con él; y Pisístrato entraba en carro, con la mujer caminando a su lado, y los de la ciudad haciendo muestras de reverencia le recibieron con admiración. (Arist. Ath. Pol. 14.4) ${ }^{14}$

Este "según dice Heródoto» podría tener dos finalidades. La primera, mostrar su escepticismo. Al igual que el de Halicarnaso, Aristóteles no se cree del todo que este acontecimiento pudiera haberse producido, de ahí que se vea en la necesidad de decir a quién sigue. La segunda, exponer explícitamente su fuente, porque, a diferencia de otros hechos de la tiranía de los Pisistrátidas, en esta ocasión no se basa únicamente en los atidógrafos, sino en Heródoto ${ }^{15}$. Aristóteles también parece seguir a Heródoto al abordar la batalla de Palene, que marcaría su segundo regreso:

Al undécimo año de nuevo [Pisístrato] comenzó a intentar recuperar por la fuerza el poder, con el esfuerzo de otros muchos, y especialmente de los tebanos y Lígdamis el de Naxos, además de los caballeros que gobernaban en Eretria. Después de vencer en la batalla de Palénide, tomó la ciudad y quitó las armas al pueblo, y retuvo ya la tiranía con firmeza. (Arist. Ath. Pol. 15.2-3)

A diferencia de Heródoto y Aristóteles, el resto de fuentes que se refieren a estos exilios lo hacen solo tangencialmente. Algunas se limitan a mencionar el episodio del carro, este retorno de Pisístrato junto a Fía, pero sin especificar a qué expulsión corresponde (Val. Max. Paris, 1.2, ext. 2; Hermog. Inv. 1.104) ${ }^{17}$. Y aquellas que aluden a la batalla de Palene apenas entran en detalles (Androción FGrH 324 F 35).

14. Traducción de M. García Valdés.

15. Rhodes, A Commentary, 189; García Valdés, Aristóteles, 29. Plácido, «Pisístrato», 66, observa también que la Constitución de los atenienses considera, al igual que Clidemo, el primero de los atidógrafos, que Fía actuaba como parabates. De ahí que podamos deducir que Aristóteles conoce otras fuentes sobre este episodio concreto.

16. Traducción de M. García Valdés.

17. Tanto Valerio Máximo como Hermógenes son fuentes tardías y puede que no se refieran explícitamente a qué retorno pertenece el episodio porque con el paso del tiempo se ha perdido el recuerdo. 
Para Plutarco (Sol. 30.6) Megacles no habría estado siquiera en la batalla de Palene porque habría huido de Atenas después de que a Pisístrato se le concediera la guardia personal que dio paso a su primera tiranía. Paradójicamente, en otra obra suya (los Moralia) reconoce que los Alcmeónidas - sin referirse de forma explícita a Megacles- habrían llegado a un acuerdo con el tirano para que volviera de su exilio a cambio de casarse con la hija de su líder. En esta segunda obra no solo omite por completo el episodio del carro (iincredulidad u olvido?), sino que, al igual que en el caso de Aristóteles, sabemos que está siguiendo de manera directa a Heródoto porque le acusa de imputar injustamente el cargo de traición a los Alcmeónidas por la actuación de estos con los persas años después (Mor. 858c).

Será ya en torno a la segunda mitad del siglo II de nuestra era cuando Polieno entremezcle por vez primera -entre las fuentes que se nos han conservado al menos- en su obra Estratagemas el regreso en el carro y la batalla de Palene:

Pisístrato desde Eubea marchó sobre el Ática por Palénide, y a los primeros enemigos sobre los que cayó los mató a todos. Avanzando se encontró con otros mucho más numerosos. Dio la orden de coronarse con un ramo de olivo y no matar a los que les salieran al paso, sino decir que habían pactado con los primeros. Ellos, como es natural, le creyeron, pactaron con él y le entregaron la ciudad. Pisístrato, después de subir a un carro y colocar a su lado a una mujer alta, hermosa, de nombre Fía, adornada con las armas de Palas, para dar la impresión de que Atenea guiaba a Pisístrato, entró tranquilamente en la ciudad y se hizo con la tiranía de Atenas. (Polyaenus, Strat. 1.21.1) $)^{18}$

La treta que siguió Pisístrato para hacerse con el control total de Atenas arrebatando las armas a sus conciudadanos (Polyaenus, Strat. 1.21.2) parece inspirada en Aristóteles (Ath. Pol. 15.4). Dicha estratagema está ausente en Heródoto, quien se limita a mencionar, tras narrar la batalla de Palene, la purificación de Delos (Hdt. 1.64.2), dando así por terminada su digresión sobre los Pisistrátidas ${ }^{19}$.

Finalmente, Apolodoro añade algo de información sobre Fía, la mujer protagonista del episodio del carro. Siguiendo, por un lado, a Filarco (FGrH $81 \mathrm{~F} 2$ ), se limita a decir que era una mujer bella que le permitió

18. Traducción de J. Vela Tejada y F. Martín García.

19. A pesar de su ausencia en Heródoto, no hay motivos para no dar validez aquí a Aristóteles en determinados aspectos de su narrativa. Incluso con las variaciones de Polieno, que parece recoger también otra tradición, los hechos siguen aconteciendo en el ágora vieja de Atenas. 
recuperar la tiranía, sin especificar si su actuación tuvo lugar durante el primer o segundo retorno. Por otro lado, siguiendo a Clidemo (FGrH 323 F 15) en su libro octavo de los Retornos, añade que Pisístrato le habría dado a Fía como esposa a su hijo Hiparco ${ }^{20}$. Por desgracia, esta obra de Clidemo no se ha conservado y, con toda seguridad, sería una fuente muy útil para discernir sobre si el episodio del carro de Atenea tuvo lugar tras el primer o el segundo exilio de Pisístrato.

\section{Propuesta alternativa de Datación}

A la vista de todo lo expuesto, podemos observar que, aunque hay documentadas varias fuentes antiguas que hablan sobre el episodio del carro, solo son dos los autores conservados de los que parten los testimonios de los demás: Heródoto y Aristóteles. En este sentido, si tenemos en cuenta la incredulidad que muestra al respecto el Estagirita, quien, además, explícitamente afirma seguir a Heródoto, queda patente que nos encontramos ante una única fuente inicial (fruto o no de una tradición oral): el propio Heródoto. Nuestro objetivo a continuación es explicar por qué creemos que este episodio se habría llevado a cabo en el segundo y último retorno de Pisístrato a la tiranía, considerando para ello la fecha de 546, que es la comúnmente aceptada para la batalla de Palene.

1) En primer lugar, como ya insinuamos, a nivel literario da la impresión de que Heródoto desplaza, consciente de ello o no, el foco de atención hacia otro elemento que no es el acuerdo entre Megacles y Pisístrato. Aunque es cierto que no debemos imaginar al de Halicarnaso como un mero propagandista alcmeónida ${ }^{21}$, ello no implica la ausencia de Alcmeónidas entre sus informantes, que pretendiesen descargar de responsabilidad la connivencia existente entre un antepasado suyo y

20. Davies, Athenian, 452, piensa que este matrimonio no se habría llevado a cabo, no solo por lo tardía que es la fuente, que en realidad no lo es tanto, puesto que Clidemo es de finales del siglo IV, igual que Aristóteles, sino porque al haber sido el regreso de Pisístrato con Fía hacia el año 557, Hiparco no habría sido lo suficientemente mayor. Al haber retrasado este regreso con Fía diez años, este segundo supuesto no se aplica. El hecho de que Tucídides (6.55.1) mencione que Hiparco no había tenido hijos o que nadie antes de Clidemo lo comentase no apunta en una dirección contraria, aunque para Davies (ibid.) sí lo haga. Lavelle, Fame, 133, por su parte, se limita a considerar este testimonio confuso y añade que podría referirse al matrimonio de uno de los hijos de Pisístrato con la hija de un notable tracio.

21. Lateiner, The Historical, 133. 
el primer tirano ateniense ${ }^{22}$. Podía existir cierta motivación política de fondo para tergiversar este punto concreto de la historia de la tiranía: centrar la atención de la audiencia en la teatralización de la entrada de Pisístrato. De hecho, no sería la única ocasión en la que informantes alcmeónidas de Heródoto encaminan su narración por otros derroteros que se salen de lo plenamente histórico, como demostró hace poco Lavelle ${ }^{23}$ a propósito del episodio de Hipóclides y Clístenes de Sición.

2) También en un nivel más literario que histórico debemos llamar la atención sobre las importantes similitudes existentes entre los episodios de Heródoto correspondientes al carro y a la batalla de Palene ${ }^{24}$. Cuenta Heródoto en el pasaje de Atenea que Pisístrato mandó a unos heraldos para avisar a los atenienses de que no le temieran, igual que hace en la batalla de Palene con sus propios hijos. Los "heraldos" ( de Pisístrato en el segundo. La escasa violencia tanto en su primera vuelta como en la segunda nos induce a pensar que se trata de un episodio que sigue patrones mnemotécnicos. La batalla de Palene actúa casi como un "doblete" de la vuelta anterior. Asimismo, la presencia hoplítica resulta común en ambos pasajes, en el primero por la armadura de Atenea, en el segundo por el ejército de Pisístrato. Y lo mismo sucede con el retorno a la acrópolis en ambos casos: aunque en el segundo no lo diga abiertamente Heródoto, queda mencionado de forma explícita por Aristóteles (Ath. Pol. 15.4).

3) En un plano ya netamente histórico, mediante un simple análisis contrafactual, podemos ver que, de haberse producido el retorno en el carro de Atenea la primera vez y no la segunda, los Alcmeónidas podrían haberse reafirmado como sacrílegos hacia la diosa. Pisístrato evitó tener descendencia con la hija de Megacles porque se decía «que los Alcmeónidas estaban malditos» (Hdt. 1.61.1). A esta familia todavía en el siglo VI y en el V (con Pericles) le perseguía su condición de sacrílega desde el intento de tiranía de Cilón en el VII. Su imagen estaba tan denostada que Pisístrato se negaba a tener una descendencia común. ¿Cómo iba un Alcmeónida como Megacles a atreverse después a ir contra Pisístrato, ya tirano por segunda vez, cuando este

22. Para Lavelle, Fame, 100, al igual que para nosotros, la fuente es probablemente más alcmeónida que herodotea (no cree que tenga su origen en el de Halicarnaso).

23. Lavelle, "Hippokleides».

24. Algunos de estos parecidos fueron detectados también por Blok, "Phye's Procession", 40-41. 
gozaba del favor de Atenea a ojos de los demás atenienses? ¿No iba a traducirse esa decisión de expulsarlo por segunda vez en un nuevo episodio de ofensa a la diosa? ¿Acaso no sería considerada esta acción un nuevo acto de impiedad?25. Resulta más probable que el retorno del carro sucediera tras la batalla de Palene, sin que nadie se atreviese a arremeter contra Pisístrato. Megacles, en su condición de Alcmeónida, no se habría arriesgado a ir en contra de quien se habría mostrado como un fiel defensor de Atenea apenas un año después de esta supuesta teatralización.

4) Desde una perspectiva geográfica, conviene atender al lugar de procedencia de Fía. Heródoto y Aristóteles coinciden en señalar que la joven vestida de Atenea procedía del demo de Peania. Tanto si se

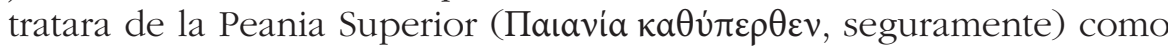

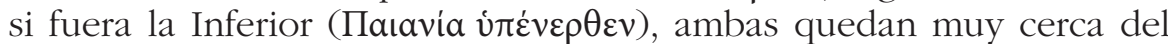
santuario de Atenea en Palene, por lo que habría sido más probable para Pisístrato hacerse con dicha muchacha antes o inmediatamente después de la contienda, en su camino desde Maratón durante su segundo regreso, y no durante el primero. Además, en caso de haber sido tracia (planteaba Aristóteles que quizá lo fuera), Pisístrato tuvo mayores contactos con los tracios durante su segundo exilio (y no a lo largo del primero), ya que se afincó en la Calcídica durante varios años ${ }^{26}$.

5) Desde una perspectiva política, este episodio del carro tiene también un mayor sentido en el segundo retorno que en el primero porque responde a la necesidad que tiene Pisístrato de ser aceptado por el demos ateniense cuando no cuenta con otros apoyos dentro del asty. Habiendo llegado a un acuerdo con Pisístrato, Megacles no tenía necesidad alguna de impresionar al demos con su regreso. Como influyente aristócrata, Megacles gozaría ya de sus respectivas redes clientelares ${ }^{27}$. Incluso en el caso de que fuera Licurgo, el tercer líder político en liza, quien tuviese el dominio de la polis (algo que, recordemos, no señala ninguna fuente) ${ }^{28}$, la unión entre el Pisistrátida, el Alcmeónida

25. Contra Gernet, Antropología, 311, que cree que Megacles se beneficiaría más que Pisístrato por haber sido él quien hizo el ofrecimiento del pacto.

26. Así se desprende de la afluencia de fondos que recibe de la región del río Estrimón (Hdt. 1.64.1; y de manera explícita en Arist. Ath. Pol. 15.2).

27. Lavelle, Fame, 99, destaca sobre todo su riqueza, chremata, frente a la popularidad de Pisístrato.

28. Heródoto (1.60.1) incluso dice que, tras la primera expulsión de Pisístrato, siguió el enfrentamiento entre las facciones de Megacles y Licurgo. 
y sus respectivos seguidores podría haberlo desplazado del poder de la misma forma que en su momento la alianza entre las facciones de Licurgo y Megacles permitió el primer exilio de Pisístrato (Hdt. 1.60.1). Presenta mayor coherencia, por tanto, que Pisístrato se sirviese de la escenificación de Atenea y el carro después de una batalla que perseguía una aceptación interna cuyo alcance desconocía.

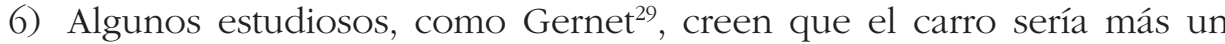
símbolo de triunfo y matrimonio que de lucha ${ }^{30}$. Aunque estamos de acuerdo en el elemento de triunfo, no podemos sino disentir sobre el aspecto nupcial en este contexto. Como bien recuerda Connor ${ }^{31}$, Atenea, por su condición de virgen, no es una diosa que se asociase a la fertilidad o a este tipo de enlaces matrimoniales, sino que tiene un carácter más guerrero ${ }^{32}$. También se encarga de recordarlo el propio Homero en la Ilíada (5.428-430), cuando al dirigirse a Afrodita Zeus le dice: "Hija mía, a ti no te están dadas las bélicas empresas, tú ocúpate de las deseables labores de la boda (del gamos), que de todo esto se cuidarán el impetuoso Ares y Atenea "33. Atenea es, por tanto, una diosa eminentemente guerrera (salvo contadas excepciones). De hecho, el propio Polieno (1.21.1) especifica que Pisístrato viene acompañado de una Pallas Atenea, esto es, Atenea en advocación guerrera (siguiendo, quizá, a Heródoto, que también habla de su panoplia). Nos encontramos ante una escenografía con claras connotaciones bélicas y no matrimoniales.

7) Un séptimo argumento para situar el episodio del carro de Pisístrato en su segundo regreso tiene que ver, en la línea con nuestro punto anterior, con la escenografía de guerra, con la presencia de elementos como son el carro y la armadura. Los carros se llevan a una batalla

29. Gernet, «Mariages», 52.

30. Sinos, "Divine Selection", 75, recuerda que los carros también eran utilizados en procesiones nupciales, pero creemos que ello no es suficiente para el caso que aquí contemplamos.

31. Connor, "Tribes, Festivals», 43, cree que esos aspectos más relacionados con el matrimonio, sí presentes en el episodio, serían desarrollados con posterioridad y es lo que en parte hace que se origine la historia entre Hiparco y Fía.

32. Para temas relacionados con el matrimonio suele ser más común la presencia de Hera, quien era la diosa por antonomasia de este ámbito. Atenea es una diosa guerrera y el casi único elemento más vinculado al mundo femenino que conserva es el del tejido, al margen del matrimonio. Solía asociarse más al carro, a la conducción de caballos o a la brida (cf. Parker, On Greek Religion, 94-95, 195, 221).

33. Traducción de E. Crespo Güemes. El carácter no guerrero de Afrodita, sin embargo, puede ser matizado, ya que existía cierta influencia proximooriental durante el Alto Arcaísmo que pudo haberla dotado del mismo (cf. Valdés Guía, El papel, 104-112). 
antes de luchar. Es posible que Pisístrato lo utilizase con el objetivo de parecerse a Heracles $^{34}$ y buscando remitir a tiempos homéricos, o bien que tratase de hacer alusión a su gloria pasada por la guerra de Mégara. Sin embargo, al margen de la motivación inicial, ya de por sí tiene mayor razón de ser que Pisístrato vaya en carro durante y después de una contienda militar, mostrándose como un héroe, entrando en Atenas con cierta velocidad, a la par que sus enemigos huyen buscando refugio. Habría que añadir que, aunque Heródoto diga que los Alcmeónidas «se toparon con ellos [las tropas de Pisístrato] al llegar al santuario de Atenea Palénide», este encuentro no es casual, no ya por el carácter guerrero que presentaba Atenea, que llevaba una armadura hoplítica completa (Hdt. 1.60.4), lo cual refleja una intención previa de presentar batalla, sino por tratarse asimismo de un lugar de paso de cierta relevancia en el Ática. Palene es un punto geoestratégico crucial en la conexión entre el norte y el sur del Ática, entre la llanura del Pedión y la Paralia ${ }^{35}$. La cita bélica se produce cuando Pisístrato está descendiendo desde Maratón (Hdt. 1.62.2) y los del asty se dirigen para luchar contra él. No es un encuentro fortuito. No se puede afirmar que Pisístrato no tuviera tiempo siquiera de idear esta argucia de cara a su segundo regreso, sino que, de hecho, le era muchísimo más útil llevarla a cabo en este momento y en este lugar, en 546 y en Palene.

8) Quizá la evidencia más palpable que muestra que nos encontramos ante una Fía caracterizada como Pallas, y que prueba que estamos, pues, ante un trasfondo bélico en el episodio del carro, es la cerámica que se nos ha conservado de mediados y finales del siglo VI. No son pocas las imágenes en vasos cerámicos de figuras negras primero, y rojas después, que ofrecen iconografía con la representación de Atenea sobre un carro junto a otras figuras, sobre todo Heracles ${ }^{36}$. Además, algunas de esas escenas parecen estar relacionadas con la lucha contra los gigantes, los cuales tienen una estrecha vinculación con Palene, como es el caso de Alcioneo, que incluso habría nacido

34. Sobre una posible identificación entre Pisístrato y Heracles gracias al episodio del carro se ha escrito sucintamente, sobre todo Boardman ("Herakles, Peisistratos and Sons"; «Herakles, Peisistratos and Eleusis» $\mathrm{y}$ "Herakles, Peisistratos and the Unconvinced»), aunque no le han faltado detractores en algunas de sus observaciones, como Cook ("Pots and Pisistratan", 168-169), Shapiro (Art and cult, 15-16) o Ferrari ("Héraclès», 219-226).

35. Valdés Guía, El nacimiento, 142.

36. Shapiro, Art and cult, 37-40. Hay también otras que representan a Erictonio (cf. LIMC s. v. Erectheus, n. ${ }^{\circ}$ 50; Shear, Polis, 518; Parker, Polytheism, 254-255). 
allí (PMG 985b) $)^{37}$. En este sentido, cabría llamar la atención sobre un ánfora del pintor Lisípides con una decoración particular relacionada con la lucha contra los gigantes, de $c .520$, en la que se muestra a un hombre sobre un carro (¿podría ser Pisístrato?), junto a Heracles y Atenea.

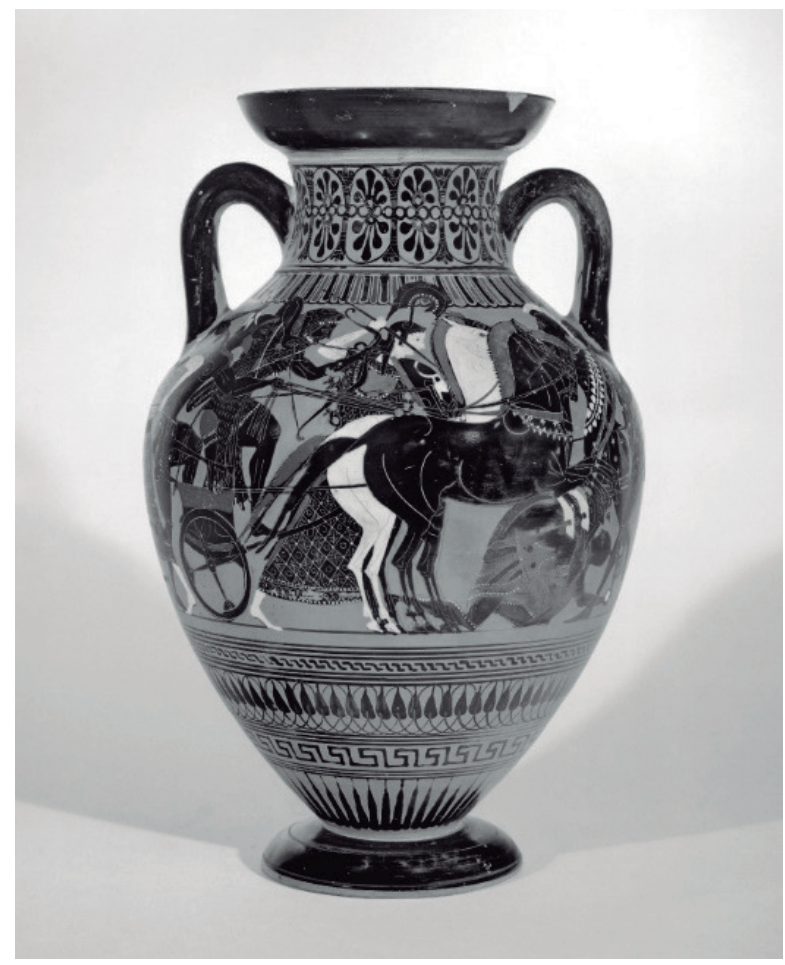

Anfora de Lisipides (British Museum, $n .^{\circ}$ Inv. 1839, 1109.3). (C) The Trustees of the British Museum. Shared under a Creative Commons Attribution-NonCommercial-ShareAlike 4.0 International (CC BY-NC-SA 4.O) licence.

9) El segundo retorno de Pisístrato y la batalla de Palene tienen lugar, a diferencia del primero, en un año de Grandes Panateneas ${ }^{38}$. Hay por tanto elementos iconográficos y míticos en el imaginario ateniense

37. Apolodoro (1.6.1) dice que, de acuerdo con algunas versiones, todos los gigantes habrían nacido en Palene. Según otras, en Flegra.

38. Phillips, "Athenian Political History», 205. Shear, Polis, 521, contempla que ese año se habrían celebrado antes de que llegara Pisístrato. 
del siglo VI que deben ser tenidos en cuenta a la hora de entender esta vuelta de Pisístrato sobre el carro y que, desgraciadamente, no han gozado de la atención que merecen por parte de la historiografía reciente. Sin comprender que esta vuelta se produce en un año de Grandes Panateneas no se puede entender del todo este coup de théâtre. Erictonio no solo habría sido el instaurador de las Panateneas, sino que, además, habría sido el inventor del carro, que condujo por primera vez durante la también primera celebración de esta fiesta ${ }^{39}$. Pisístrato se está identificando en su episodio del carro con el mismo Erictonio. Algo en lo que ya reparó Deacy ${ }^{40}$, pero sin apreciar que pudiera ser en su segundo regreso. El tirano pasa tras la batalla de Palene a formar parte de una pompe. No de una procesión cualquiera, sino de la de un año de Grandes Panateneas. Deja de ser un exiliado para formar parte, de nuevo, del cuerpo cívico de Atenas. Recrea con Fía disfrazada de Atenea una procesión propia de las Panateneas: con carácter centrípeto ${ }^{41}$, con un punto de origen en la periferia (no en este caso la Academia o el Cerámico, pero sí Palene, que es una región fronteriza) y con un punto final que es la acrópolis (Arist. Ath. Pol. 15.4), y cuyos participantes son fundamentalmente hoplitas ${ }^{42}$.

10) Dentro de este marco contextual de Grandes Panateneas se entiende mejor la iconografía cerámica que representaba a Atenea en un carro junto a Heracles luchando contra los gigantes. Si ya vimos que durante el episodio del carro Pisístrato iba acompañado de una Atenea que muestra su carácter guerrero, y la cerámica nos confirma esta presencia habitual de la diosa en escenas de Gigantomaquia, el hecho de que su segundo retorno se produzca en un año de Grandes Panateneas no deja de ser un guiño más, pues, a este imaginario ateniense del siglo VI. En las Grandes Panateneas se festeja la victoria contra los gigantes y algo similar podría estar tratando de emular Pisístrato ${ }^{43}$. Los gigantes

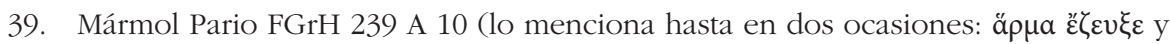

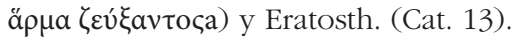

40. Deacy, «Famous Athens", 232.

41. De la Nuez Pérez, «Las Panateneas», 103; Forsdyke, Exile, 114-115.

42. No sería el primero que intentara alcanzar la tiranía de Atenas en el momento en el que toca la celebración de una fiesta. Ya lo había pretendido con anterioridad Cilón, al seguir erróneamente un consejo del oráculo de Delfos (Hdt. 5.71; Arist. Ath. Pol. Fr. 8).

43. De hecho, en la ofrenda que recibía Atenea, en el peplo, se solía representar un carro y su lucha contra los gigantes (Schol. Aristid. Panath. 197,8 Dindorf; Valdés Guía, "Atenea Nike», 108). 
eran criaturas autóctonas (como los Alcmeónidas: Hdt. 5.62.2) ${ }^{44}$, que lucharon contra los dioses y el extranjero Heracles (como Pisístrato). La victoria de los segundos se produce después de una batalla (como la de Palene), no tras un enlace matrimonial.

11) Asimismo, también en las Grandes Panateneas de 546 el agon gymnicus está vigente. El carro, más que un elemento nupcial, es sobre todo un símbolo agonístico. Los carros eran utilizados en el período arcaico no solo para honrar a los dioses, sino también para celebrar el honor de aquellos humanos victoriosos en los Juegos ${ }^{45}$. La llegada de Pisístrato sobre un carro durante su segundo retorno ejemplificaba también a nivel competitivo su prominencia, su arete sobre la de un Megacles que no había podido vencerlo en la batalla de Palene. Pisístrato es un aristócrata que vence a otro aristócrata, Pisístrato llega ya a Atenas como ganador de una contienda bélica, pero también de un agon. Ya antes de la propia batalla de Palene cuenta Polieno (1.21.1) que Pisístrato se corona con una rama de olivo, acción que sucedía tras salir victorioso de un agon. Tras la derrota de su principal rival recupera su gloria, su kleos, y, con ello, la tiranía por tercera y última vez.

12) Por último, a nivel social, debemos recordar que el grueso de los seguidores de Pisístrato pertenecía al sector socioeconómico más bajo (Hdt. 1.59.3; Arist. Ath. Pol. 13.5; Plut. Sol. 29.1). Al futuro tirano le convenía llevar a cabo la batalla de Palene no solo en un contexto de Grandes Panateneas, sino en una época del año en la que sus seguidores pudieran participar. La recolección de parte de las cosechas había terminado ya (Hes. Op. 574-582; 598-600), lo que abocaba a la falta de trabajo de muchos de ellos hasta septiembre (609-618). Asimismo, es en los meses de verano cuando más fácil resulta navegar (664-671), algo que habría beneficiado a a Pisístrato para desembarcar en Maratón. Le habría facilitado el apoyo de Lígdamis (Hdt. 1.61.4; Arist. Ath. Pol. 15.2-3), llevar a Naxos a sus prisioneros (Hdt. 1.64.1) y dirigirse inmediatamente después a Delos para purificarlo (Hdt. 1.64.2; Thuc. 3.104.1-2), buscando así mayor legitimidad.

44. Cabe recordar también que Palas y los Palántidas eran de la Paralia, lugar de procedencia de los Alcmeónidas (cf. Valdés Guía, El nacimiento, 141).

45. Sinos, "Divine Selection", 74. Los carros también servían para transportar en la lucha y en la batalla (p. 76). Coincidimos con este autor (p. 78) en que, entrando de esta manera en Atenas, Pisístrato se mostraba como un hombre victorioso, pero discrepamos en que lo hiciera como un superhuman. También lo critica Lavelle, Fame, 100, para quien Sinos lleva su propuesta muy lejos al considerar que Pisístrato "was attempting to join the ranks of other distinguished rulers who presented their laws and reforms as the will of the gods". 
En definitiva, a la luz de todo lo expuesto, no nos queda sino considerar que el episodio del carro se habría llevado a cabo en el segundo regreso de Pisístrato, durante y después de la batalla de Palene de 546. Puede que todavía haya escépticos que consideren que este relato es tan solo un cuento popular (como decía Moon) ${ }^{46}$ y que no hay una historia real detrás. Sin embargo, incluso considerando esta última posibilidad, que en realidad Pisístrato no se hubiese atrevido a llevar a cabo esta parafernalia y todo fuera fruto de una larga tradición oral, en dicho caso deberíamos estar hablando aquí de un relato que narra una epifanía que, a su vez, también tiene mayor razón de ser en un segundo regreso que en el primero. Como recuerda Sinos, no sería algo inusual, pues las epifanías son comunes en otras batallas que nos narran las fuentes griegas ${ }^{47}$. Atenea defendería con su presencia en la batalla a los que consideraba los «verdaderos» atenienses frente a los usurpadores, con Megacles a la cabeza ${ }^{48}$, convirtiéndose así Heródoto en el único responsable de situar este acontecimiento en el primer regreso.

\section{INTERPRETACIÓN DEL EPISODIO DEL CARRO}

Aclarada por el momento la datación de este episodio que sí consideramos histórico, debemos comentar los motivos principales que habrían llevado a Pisístrato a emplear una estratagema de estas características. Algunas razones han sido ya sucintamente expuestas en el apartado anterior, pero quedan todavía tres cuestiones que podrían ayudar a entender mejor la instrumentalización de la diosa Atenea por parte de Pisístrato, asî como otras intenciones de fondo.

El primero de los motivos para llevar a cabo esta teatralización puede que sea uno de los más evidentes si atendemos al aspecto bélico en el que enmarcamos el episodio. Pisístrato pudo haber tratado de recrear una

46. Moon, «The Priam Painter", 97-118.

47. Sinos, "Divine Selection", 79 con ejemplos.

48. Paradójicamente, entre las tropas de Pisístrato no habría en su mayoría atenienses (cf. Lavelle, Fame, 139-142). Como demostró este mismo autor (pp. 18-19), pudo haber sido un problema para algunos atenienses la condición de extranjeros de los Pisistrátidas. La aceptación de héroes no áticos como Heracles por parte de los atenienses repercutía en el propio beneficio de un tirano «extranjero» que también necesitaba dicha aceptación. De hecho, fue gracias a la adopción de Heracles por Pilios como este héroe pudo iniciarse en los misterios de Eleusis y llevar a cabo su último trabajo (Apollod. Bibl. 2.5.12; Diod. Sic. 4.14.3). Pisístrato no se alejaba de esta idea mítica: ser aceptado por sus conciudadanos le permitía participar en igualdad de condiciones en sus fiestas religiosas y convertirse, por tanto, en uno más. 
epifanía. No se trataría solo de un relato posterior, sino de una actuación histórica real mediante la cual el futuro tirano haría que la diosa-Fía se posicionase durante la batalla de Palene en favor de uno de los bandos. Por supuesto, conviene recordar que no es que los atenienses se dejasen engañar y creyesen que en realidad era la verdadera Atenea la que estaba luchando contra ellos, sino que, como mostró convincentemente Connor $^{49}$, esta teatralización habría requerido sin duda de la complicidad de sus seguidores. Se trataría de una aceptación bilateral, algo que no es nada inusual en otras culturas y religiones de la actualidad, como cuando se produce la transubstanciación del pan y el vino en las eucaristías propias de la Iglesia ortodoxa del este de Europa ${ }^{50}$ o la presencia "real» de la virgen durante las procesiones de Semana Santa en la España católica. El episodio del retorno del carro de Pisístrato es, por tanto, uno de los mejores ejemplos documentados del período de tiranía sobre la complicidad existente entre el demos y el futuro tirano ${ }^{51}$.

La segunda razón por la que Pisístrato habría ideado esta treta se presenta de manera implícita tanto en Heródoto como en Aristóteles: facilitar su retorno a la polis, es decir, evitar en la medida de lo posible un enfrentamiento al ir junto a una representación de Palas Atenea. Pisístrato se inscribe así dentro del imaginario mítico ateniense del siglo VI en vísperas de Grandes Panateneas. A través del episodio del carro, Pisístrato quedaría identificado para Lavelle ${ }^{52}$ como una mezcla particular de varios héroes y referentes mitológicos como Diomedes, que fue conducido a la guerra contra Ares por Atenea, y quizá Odiseo. De hecho, unos años antes, creemos que ya Blok acertaba al considerar que Pisístrato estaba

49. Connor, «Tribes, Festivals», 44. Una complicidad que también existe en el caso de las estatuas. Como dice Parker, On Greek Religion, xi: «they [the Greeks] constantly behaved and spoke as if their statues were gods: when a statue of Dionysus was brought in procession to the theater at the start of the Athenian Dionysia, this was not a 'representation of the bringing in of Dionysus' but quite simply 'the bringing in of Dionysus'». También acepta esta postura Forsdyke, "Herodotus», 236.

50. Sinos, «Divine Selection", 84 .

51. Aristóteles (Ath. Pol. 13.5) diría que Pisístrato era el líder de las masas, el más demótico, que no democrático (como traduce M. García Valdés). Sin embargo, Pisístrato

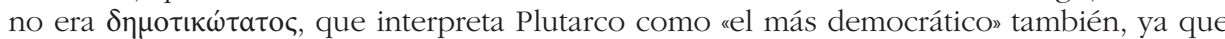
el futuro tirano se apoya sobre una base social baja, más que los otros, con el sencillo fin de instrumentalizarla para hacerse con el gobierno de la polis. La división política que Aristóteles primero, y más adelante haría Plutarco (Sol. 29.1), debe circunscribirse a las teorías políticas imperantes en los siglos V y IV, en los que Pisístrato, en tanto que tirano, representaba lo peor del demos (cf. Holladay, «The followers», 40-41; apuntado ligeramente con anterioridad por Hopper, "Plain', 'Shore'»).

52. Lavelle, Fame, 103-105. 
emulando con su esperado regreso la vuelta del propio Odiseo a Ítaca ${ }^{53}$. Asimismo, y en virtud de nuestra disquisición anterior, en la que atendemos al contexto de Grandes Panateneas, creemos también que podría haberse producido una identificación con Heracles o Erictonio. Pisístrato es el Heracles que representa la victoria contra los gigantes. El que ayuda a Atenea a regresar a su acrópolis tras una dura lucha. Con respecto a Erictonio, su vinculación sería más indirecta, pero en tanto que creador mítico de la fiesta más importante de Atenas, el primero en haber llevado una cuadriga en la procesión de esta fiesta, también habría sido posible. Pisístrato necesita ser aceptado como tirano y como ateniense en un momento en el que no goza de ningún valedor aristócrata autóctono dentro de la polis, como en el primer retorno lo fue Megacles, que facilitó su segunda consecución de la tiranía.

Finalmente, esta actuación lleva al que es el objetivo último de Pisístrato, ganar legitimidad como tirano a través de un elemento religioso, en este caso en concreto la instrumentalización de la diosa principal de Atenas en su advocación guerrera. Atenea Pallas lleva a su acrópolis a Pisístrato como en su momento conduce a Heracles al Olimpo. Atenea regresa a su casa de la misma forma en la que traslada a Pisístrato a la que sería la suya. La diosa acoge al futuro tirano en la acrópolis delante del resto de atenienses, ¿cómo iban a echarlo entonces los demás? En definitiva, como señala con acierto Aristóteles (Pol. 1315a1-3) cuando escribe sobre los medios de legitimación de los gobiernos unipersonales, se atentaba menos contra aquel que tiene a los dioses como aliados (kaì

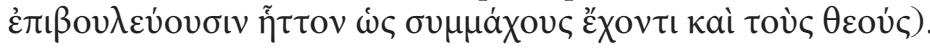

\section{BibliografíA}

Adcock, Frank E. «The Exiles of Peisistratus». Classical Quarterly 18.3 (1924): 174-181.

Asheri, David. «Book I». En A Commentary on Herodotus. Books I-IV, editado por Oswyn Murray y Alfonso Moreno, 57-218. Oxford: Oxford University Press, 2007.

53. Plutarco (Sol. 30.1) reconstruye un diálogo, sin duda espurio, en el que Solón se refiere a Pisístrato como Odiseo, aunque no en referencia a este episodio, sino a su primer intento de tiranía, en el que aparece también con un carro en el ágora, según cuenta Heródoto (1.59.4). Blok, «Phye's Procession», 41-43, cree que la identificación de Pisístrato con Odiseo habría sido clave en su victoria de Palene. Se percata, además, de que la pa-

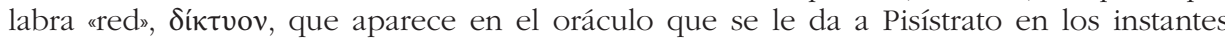
previos a la contienda (Hdt. 1.62), está presente también en hexámetros en los poemas homéricos una vez, cuando Odiseo ha matado ya a los pretendientes (Hom. Od. 22.381-387). 
Beloch, Julius. «Wann lebten Alkaeos und Sappho?». Rheinisches Museum 45 (1890): 465-473.

Blok, Josine H. "Phye's Procession: Culture, Politics and Peisistratid Rule». En Peisistratos and the Tyranny. A Reappraisal of the Evidence, editado por Helen Sancisi-Weerdenburg, 17-48. Amsterdam: J. G. Gieben, 2000.

Boardman, John. "Herakles, Peisistratos and Sons». Revue Archéologique 1 (1972): 57-72.

Boardman, John. "Herakles, Peisistratos and Eleusis». Journal of Hellenic Studies 95 (1975): 1-12.

Boardman, John. «Herakles, Peisistratos and the Unconvinced». Journal of Hellenic Studies 109 (1989): 158-159.

Carty, Aideen. Polycrates, Tyrant of Samos. New Light on Archaic Greece. Stuttgart: Franz Steiner Verlag, 2015.

Connor, Walter R. «Tribes, Festivals and Processions; Civic Ceremonial and Political Manipulation in Archaic Greece». Journal of Hellenic Studies 107 (1987): 40-50.

Cook, Robert M. "Pots and Pisistratan Propaganda». Journal of Hellenic Studies 107 (1987): 167-169.

Crespo Güemes, Emilio. Homero. Ilíada. Madrid: Gredos, 1996.

Davies, John, K. Athenian Propertied Families. 600-300 B. C. Oxford: Clarendon Press, 1971.

De la Nuez Pérez, María E. "Las Panateneas: topografía de una fiesta». Gerión 22.1 (2004): 101-120.

Deacy, Susan. "Famous Athens, Divine Polis": The Religious System at Athens». En A Companion to Greek Religion, editado por Daniel Ogden, 221-235. Oxford: Blackwell Publishing Ltd, 2007.

Gernet, Louis. "Mariages des tyrans". En Éventail de l'histoire vivante: hommage à Lucien Febvre 2, editado por Lucien Febvre, 41-53. Paris: Armand Colin, 1953.

Gernet, Louis. Antropología de la Grecia antigua. Traducción de Bernardo Moreno Carrillo. 2. ${ }^{a}$ ed. Madrid: Taurus, 1980.

Ferrari, Gloria. "Héraclès, Pisistratus and the Panathenaea». Mètis. Anthropologie des mondes grecs anciens 9-10 (1994): 219-226.

Forsdyke, Sara. Exile, Ostracism, and Democracy. The Politics of Expulsion in Ancient Greece. Princeton: Princeton University Press, 2005.

Forsdyke, Sara. "Herodotus, political history and political thought». En The Cambridge Companion to Herodotus, editado por Carolyn Dewald y John Marincola, 224-241. Cambridge: Cambridge University Press, 2008.

García Valdés, Manuela. Aristóteles. Constitución de los atenienses. PseudoAristóteles. Económicos. Madrid: Gredos, 1984. 
Hammond, Nicholas G. L. A History of Greece to 322 B. C. Oxford: Clarendon Press, 1959.

Holladay, James. «The followers of Peisistratus». Greece \& Rome 24.1 (1977): 40-56.

Hopper, Robert J. "Plain', 'Shore', and 'Hill' in Early Athens". Annual of the British School at Athens 56 (1961): 189-219.

Hurwit, Jeffrey M. The Art and Culture of Early Greece, 1100-480 B.C. Ithaca - London: Cornell University Press, 1985.

Larran, Francis. "La bataille de Pallèné aura encore lieu ou Pisistrate dans les rets de l'analogisme historique d'Andocide». Dialogues d'Histoire Ancienne 40.1 (2014): 53-73.

Lateiner, Donald. The Historical Method of Herodotus. Toronto - Buffalo London: University of Toronto Press, 1989.

Lavelle, Brian M. Fame, Money and Power. The Rise of Peisistratos and "Democratic" Tyranny at Athens. Ann Arbor: University of Michigan Press, 2005.

Lavelle, Brian M. "Hippokleides, the 'Dance', and the Panathenaia». Greek, Roman and Byzantine Studies 54 (2014): 313-341.

Lavelle, Brian M. Archaic Greece. The Age of New Reckonings. Hoboken: Wiley Blackwell, 2020.

Moon, Warren G. "The Priam painter: some iconographic and stylistic considerations». En Ancient Greek Art and Iconography, editado por Warren G. Moon, 97-118. Madison: The University of Wisconsin Press, 1983.

Parker, Robert. Athenian Religion. A History. Oxford: Clarendon Press, 1996.

Parker, Robert. Polytheism and Society at Athens. Oxford: Oxford University Press, 2005.

Parker, Robert. On Greek Religion. Ithaca - London: Cornell University Press, 2011.

Phillips, David J. "Athenian Political History: A Panathenaic Perspective». En Sports and festival in the ancient Greek world, editado por David J. Phillips y David Pritchard, 197-232. London: Classical Press of Wales, 2003.

Plácido, Domingo. "Pisístrato y la falsa Atenea». Arys 7 (2006-2008): 61-68.

Rhodes, Peter J. A Commentary on the Aristotelian Athenaion Politeia. Oxford: Clarendon Press, 1981.

Rose, Herbert J. «Some Herodotean Rationalisms». Classical Quarterly 34.1 (1940): 78-84.

Sancisi-Weerdenburg, Helen. "Cultural Politics and Chronology». En Peisistratos and the Tyranny. A Reappraisal of the Evidence, editado 
por Helen Sancisi-Weerdenburg, 79-106. Amsterdam: J. G. Gieben, 2000.

Schrader, Carlos. Heródoto. Historia. Libro I. Clío. Introducción de Francisco R. Adrados. Madrid: Gredos, 1977.

Shapiro, H. Alan. Art and cult under the tyrants in Athens. Mainz: Philipp von Zabern, 1989.

Shear, Julia L. Polis and Panathenaia: The History and Development of Athena's festival. Pennsylvania: Diss. Univ. of Pennsylvania, 2001.

Singor, Henk W. "The military side of the Peisistratan Tyranny". En Peisistratos and the Tyranny. A Reappraisal of the Evidence, editado por Helen Sancisi-Weerdenburg, 107-129. Amsterdam: J. G. Gieben, 2000.

Sinos, Rebecca H. "Divine Selection. Epiphany and Politics in Archaic Greece». En Cultural poetics in archaic Greece: cult, performance, politics, editado por Carol Dougherty y Leslie Kurke, 73-91. New York Oxford: Oxford University Press, 1998.

Stein-Hölkeskamp, Elke. "Tirannidi e ricercar dell'eunomia». En I Greci. Storia, Cultura, Arte, Società 2. Una Storia Greca I. Formazione, editado por Salvatore Settis et al., 653-680. Torino: Giulio Einaudi Editore, 1996.

Valdés Guía, Miriam. El papel de Afrodita en el alto arcaísmo griego. Política, guerra, matrimonio e iniciación. Messina: Polifemo, Suppl. 2, 2005.

Valdés Guía, Miriam. El nacimiento de la autoctonía ateniense: cultos, mitos cívicos y sociedad de la Atenas del s. VI a. C. Madrid: Anejo XXIII de ILU, Revista de Ciencias de las Religiones, 2008.

Valdés Guía, Miriam. "Atenea Nike, Panateneas y victoria sobre los gigantes. Conflicto interno y paz en el Ática del siglo VI a. C.». Incidenza dell'Antico 15 (2017): 105-131.

Van Wees, Hans. "Citizens and Soldiers in Archaic Athens". En Defining Citizenship in Archaic Greece, editado por Alain Duplouy y Roger W. Brock, 103-143. Oxford: Oxford University Press, 2018.

Vela Tejada, José y Francisco Martín García. Eneas el Táctico. Poliorcética. Polieno. Estratagemas. Madrid: Gredos, 1991.

Wallace, William P. "The Early Coinages of Athens and Euboia». En The Numismatic Chronicle and Journal of the Royal Numismatic Society. Volume II, editado John Walker, E. S. G. Robinson y C. H. V. Sutherland, 23-42. London: The Royal Numismatic Society, 1962. 